\title{
Negative Regulation of Wnt/ $\beta$-catenin Signaling is blocked by Wnt Signaling Component Protein Dishevelled1 Binding Aptamer (WD-Aptamer)
}

\author{
Sooho Choi ${ }^{1 *}$, Ji Hyun Kim¹, Yunseok Heo², Eun Sun Kim', Solip Choi ${ }^{1}$, \\ Weontae Lee ${ }^{2}$ and Jeong Hoon Kim ${ }^{1}$ \\ ${ }^{1}$ Nexmos, Inc, Republic of Korea \\ ${ }^{2}$ Department of Biochemistry, College of life Sciences \& Biotechnology, Yonsei University, \\ Republic of Korea
}

Research Article

Volume 5 Issue 3

Received Date: September 07, 2020

Published Date: September 25, 2020

DOI: $10.23880 /$ cdoaj-16000219

*Corresponding author: Sooho Choi, Ph.D., Nexmos, Inc, 2207 U-Tower, 767, Sinsu-ro, Suji-gu,

Yongin-si, Gyeonggi-do, Republic of Korea, Tel: 82-70-5138-0962; Fax: 82-70-8260-0300 ; Email: joon@nexmos.com

\section{Abstract}

Dishevelled1 (Dvl1), which plays an important role in Wnt/ $\beta$-catenin signaling, consists of three domains. DIX domain for Dvl1 polymerization, DEP domain for binding of Dvl1 to other signal transduction molecules, and PDZ domain for binding to the membrane bound receptor Frizzled. CXXC5 is one of several proteins that bind to Dvl1, and when these two proteins bind together, they negatively regulate the Wnt/ $\beta$-catenin signaling.

Here, we developed Wnt signaling component protein Dvl binding Aptamer (WD-Aptamer), a DNA aptamer that specifically bind to Dvl1_PDZ domain. WD-Aptamer that binds to Dvl1_PDZ domain was developed through an in vitro method of selection referred to as Systematic Evolution of Ligands by EXponential enrichment or "SELEX." The WD-Aptamer binds to Dvl1_PDZ domain with high specificity and affinity, yielding an estimated Kd of $284.8 \mathrm{nM}$. The binding of CXXC5 and Dvl1 is inhibited by WD-Aptamer and negative regulation of Wnt/ $\beta$-catenin signaling is blocked.

Keywords: Wnt/ $\beta$-catenin Signaling; WD-Aptamer; Dishevelled1; CXXC5

\section{Introduction}

Control of cell-cell communication is most important factor for generation of embryos [1]. A major mediator of cell-cell communication during embryogenesis is conserved Wnt family of secreted proteins [2]. Wnt signaling pathway regulates the transcription co-activator $\beta$-catenin controls embryonic development and homeostasis [3-8]. When Extracellular Wnt proteins bind to and activate membrane bound Frizzled receptors, Unphosphorylated $\beta$-catenin eventual translocate from cytoplasm into nucleus and activates the transcription of specific target genes. According to a recent study, Wnt signaling component protein
Dishevelled (Dvl) appear to co-express with member of proteins that contain CXXC-type zinc-finger domains, CXXC finger protein 5 [9]. The interaction of Dvl with CXXC5 regulates bone formation, hair regrowth, and wound healing, that CXXC5 inhibits differentiation by biding to Dvl [10-12].

Aptamer is a stable three-dimensional structured single strand DNA or RNA oligonucleotides that capture specific target molecules with its unique binding ability [13]. After the development of the SELEX (Systematic Evolution of Ligands by Exponential enrichment) technology by Larry Gold Research Team of Colorado University in 1990, several studies have found aptamer sequences that bind to various 
target including cells, enzymes, viruses, proteins and small molecules $[14,15]$. Compared to antibody, the advantages of aptamer are chemical synthesis [16,17], strong stability [18], chemically modifies without losing activity $[19,20]$ and nonimmune reaction [21,22]

We report, developed a breakthrough DNA aptamer (WD-Aptamer) that binds strongly to Dvl. It was confirmed by In vitro that WD-Aptamer prevents the binding of CXXC5 and Dvl to maintain Wnt signaling and activate cell proliferation.

\section{Materials and Methods}

\section{Construct Design, Protein Expression, and Purification of Dvl1_PDZ Domain}

Dvl1_PDZ domain-expressing cells were grown in LuriaBertani medium at $37^{\circ} \mathrm{C}$ until they reached an $\mathrm{OD}_{600}$ of 0.7 , at which time $0.5 \mathrm{mM}$ isopropyl $\beta$-D-thiogalactopyranoside was added, and the cells were cultured for a further $15 \mathrm{~h}$ at $18^{\circ} \mathrm{C}$. The cells were harvested by centrifugation and stored at $-80^{\circ} \mathrm{C}$. The harvested cells were disrupted by sonication in lysis buffer [ $25 \mathrm{mM}$ sodium phosphate, $100 \mathrm{mM} \mathrm{NaCl}, 5 \mathrm{mM}$ $\beta$-mercaptoethanol, and protease inhibitor cocktail (SigmaAldrich, St. Louis, MO, USA), pH 7.8]. The hexahistidinetagged fusion protein was purified by immobilized metal affinity chromatography on an Ni-NTA column (Amersham Pharmacia Biotech, Little Chalfont, UK), and the hexahistidine tag was cleaved by incubation with tobacco etch virus (TEV) protease for $12 \mathrm{~h}$ at $25^{\circ} \mathrm{C}$. The purified Dvl1_PDZ was then further purified by size-exclusion chromatography (SEC) using a HiLoad ${ }^{\mathrm{TM}}$ Superdex ${ }^{\mathrm{TM}} 75$ preparative-grade columns (Amersham Pharmacia Biotech) [23].

\section{Aptamer Screening against Dvl1_PDZ Domain using SELEX}

To select Dvl1_PDZ domain-specific aptamers, SELEX was performed. Briefly, an ssDNA library template consisting of a 30-nucleotide random region (N30) was prepared. The random regions were flanked by 15 -mer primer regions for polymerase chain reaction (PCR) with the following sequence: 5'-GAGTGACCGTCTGCCTG-N30-CAGCCACACCACCAGCC-3'. The ssDNA library was incubated with His-tagged Dvl1_ PDZ domain protein in selection buffer [ $40 \mathrm{mM}$ HEPES (pH 7.5), $102 \mathrm{mM} \mathrm{NaCl}, 5 \mathrm{mM} \mathrm{KCl}, 5 \mathrm{mM} \mathrm{MgCl}_{2}$, and $0.05 \%$ Tween-20]. After ssDNA binding, Dvl1_PDZ domain protein was partitioned by immobilizing them on Dynabeads TALON (Invitrogen, Carlsbad, CA, USA), and unbound ssDNAs were removed by washing with selection buffer. ssDNAs were extracted and amplified by conventional PCR using a 5'-OH terminal biotinylated reverse primer. A primer extension was then performed, and an enriched pool was prepared for the next round. After eight rounds of SELEX, the enriched ssDNA pool was cloned and sequenced.

\section{SEC}

Purified Dvl1_PDZ domain samples were loaded onto a HiLoad $^{\mathrm{TM}}$ 16/60 Superdex ${ }^{\mathrm{TM}} 75$ (GE Life Science) gel filtration (AKTA $^{\mathrm{TM}}$ prime) column equilibrated with the same final protein buffer [10 mM HEPES (pH 7.8) and $10 \mathrm{mM} \mathrm{NaCl}$. The SEC result was monitored by absorbance at $280 \mathrm{~nm}$. The molecular weight of the purified protein was determined with reference to the standard proteins of Dvl1_PDZ domain $(11 \mathrm{kDa})$ and WD-Aptamer (10 kDa). The molecular weight of Dvl1_PDZ domain was calculated by the following equation: $\left(\log Y=-1.2483 x+6.2868 ; R^{2}=0.9943, x=\right.$ elution volume $)$.

\section{Fluorescence Spectroscopy}

The binding constants between Dvl1_PDZ domain and aptamer were measured by an LS55 fluorescence spectrophotometer (Perkin-Elmer). Dvl1_PDZ domain protein in a buffer containing $20 \mathrm{mM}$ Tris $(\mathrm{pH} 8.0)$ and 50 $\mathrm{mM} \mathrm{NaCl}$ was titrated with aptamer to a molar ratio of 1:0 to $1: 1$ using a thermostat cuvette. The values detected at the same concentration of ligand only were subtracted for the calibration of the inherent intensities of the protein ligands. The dissociation constant $\left(K_{\mathrm{d}}\right)$ values were calculated using the following equation: $\log \left(F_{0}-F / F\right)=\log \left(1 / K_{\mathrm{d}}\right)+n \log$ [ligand], where $F_{0}$ and $F$ are the fluorescence intensities of the protein at $360 \mathrm{~nm}$ in the absence and presence of ligand, respectively, and $n$ represents the ligand-binding site of the protein.

\section{Cell penetration and Viability test}

HaCaT cells (human skin keratinocyte cell line) were cultured in Dulbecco's modified Eagle medium supplemented with $10 \%$ heat-inactivated fetal bovine serum, 100 units/ $\mathrm{mL}$ penicillin, and $100 \mu \mathrm{g} / \mathrm{mL}$ streptomycin (Gibco BRL, Grand Island, NY, USA). The cells were maintained in an incubator $\left(95 \%\right.$ air $\left./ 5 \% \mathrm{CO}_{2}\right)$ at $37^{\circ} \mathrm{C}$. Cells were seeded in 24-well plates at a density of $1 \times 10^{4}$ cells per well and allowed to grow for $24 \mathrm{~h}$ to $60 \%$ to $70 \%$ confluence. Biotinlabeled aptamers (WD-Aptamer or negative control) were added to the culture medium at a final concentration of 100 $\mathrm{nM}$ and incubated with live cells at $37^{\circ} \mathrm{C}$ for $30 \mathrm{~min}$. After incubation, the cells were fixed with $4 \%$ paraformaldehyde at room temperature for $10 \mathrm{~min}$. After fixation, cells were treated with $0.03 \%$ Triton X-100 (Sigma-Aldrich) in $1 \times$ phosphate-buffered saline and incubated with Alexa Fluor ${ }^{\circledR}$ 555 streptavidin (Invitrogen) at room temperature for 30 min in the dark. Finally, the cells were counterstained with 4,6'-diamidino-2-phenylindole (DAPI; Vector Laboratories, 
Burlingame, CA, USA), and images were obtained by a fluorescence microscope (Optinity, Korea).

Cell viability was performed via 3-(4,5-dimethylthiazol2-yl)-2,5-diphenyltetrazolium bromide (MTT) assay (Sigma-Aldrich). Cells were seeded in 96-well plates at a density of $5 \times 10^{4}$ cells per well and incubated at $37^{\circ} \mathrm{C}$ for $24 \mathrm{~h}$. After preincubation, cells were treated with various concentrations $(0.001,0.01,0.1,1,10$, and $100 \mu \mathrm{M})$ of WDAptamer for $24 \mathrm{~h}$. MTT solution (final concentration of 0.5 $\mathrm{mg} / \mathrm{mL}$ ) was added to each well, and the cells were incubated at $37^{\circ} \mathrm{C}$ for $2 \mathrm{~h}$. The supernatant medium was removed, and $100 \mu \mathrm{L}$ DMSO (Daejung, Korea) was added to each well to extract the insoluble purple formazan crystals. Absorbance was quantified at $570 \mathrm{~nm}$ using a microplate reader (Synergy HT; Bio-Tek, USA).

\section{Results}

\section{Purification of Dvl1_PDZ Domain and WD- Aptamer Selection}

Dvl1_PDZ domain was amplified by PCR. The amplified cDNA fragments were subcloned into the modified expression vector pET21b (Novagen, Madison, WI, USA) with hexahistidine tag and a TEV protease cleavage site at the $\mathrm{N}$ terminus. The recombinant plasmid was transformed into Escherichia coli (strain BL21 DE3). The construct of Dvl1_PDZ domain was made, and the overexpressed protein was purified. To identify the purification of target proteins, samples of each step were loaded on $15 \%$ sodium dodecyl sulfate-polyacrylamide gel electrophoresis (SDS-PAGE; Figure 1a).

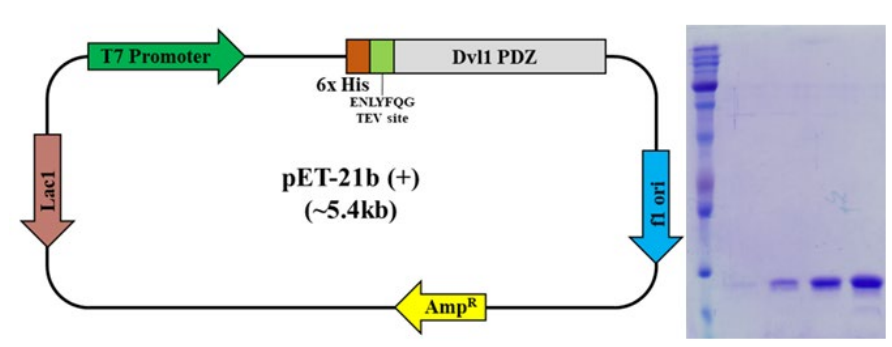

(a)

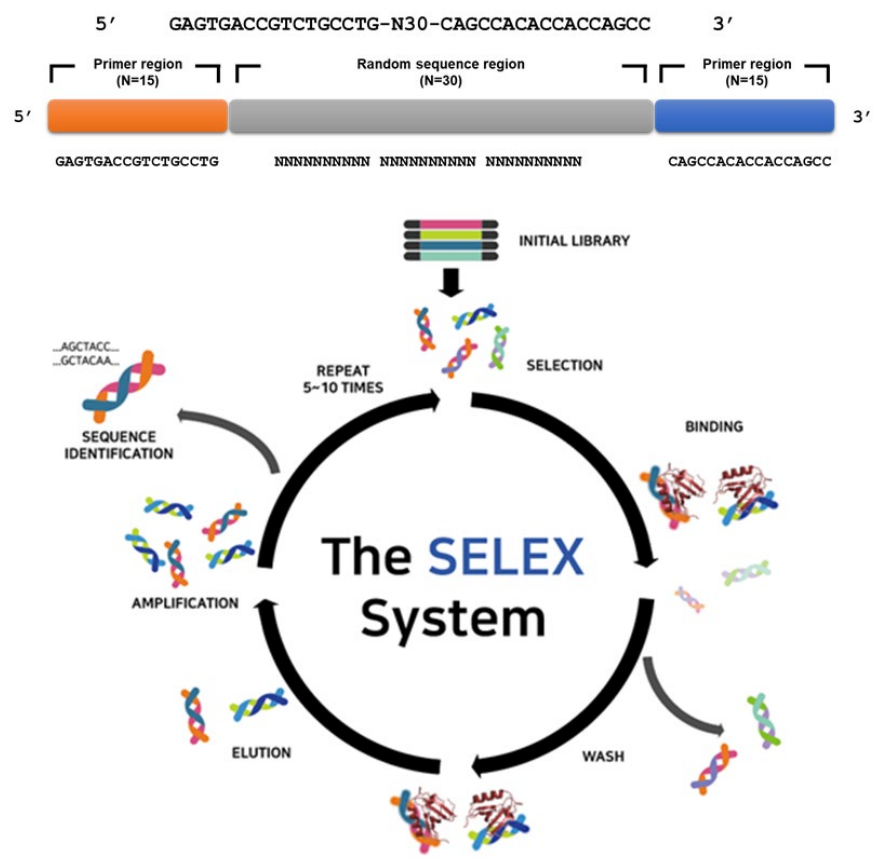

(b)

Figure 1: Purification of Dvl1_PDZ domain and WD-Aptamer selection. (a) Recombinant pET-21b (+) vector map for the expression of Dvl1_PDZ domain of mouse Dvl1. The map of E. coli expression vector containing His-tag, TEV protease cleavage site, and recombinant Dvl1 PDZ is presented as well as the purification result of SDS-PAGE. (b) General scheme of SELEX using an ssDNA library template. 
To develop WD-Aptamer, an ssDNA library template consisting of N30 was used to proceed with SELEX (Figure 1b). The output produced by SELEX produced 353,514 sequences via next-generation sequencing. Ten high-scoring candidate sequences were selected.

\section{Interaction Study of Dvl1_PDZ Domain and WD- Aptamer}

The SEC binding assay of WD-Aptamer and Dvl1_PDZ domain was studied. The experimental results show that the size of WD-Aptamer + Dvl1_PDZ domain was $20 \mathrm{kDa}$, whereas that without WD-Aptamer was $9 \mathrm{kDa}$ (Figure 2a). This result provides strong evidence that WD-Aptamer and Dvl1_PDZ domain interact. A study on the interaction of WD-Aptamer with other Wnt/ $\beta$-catenin signaling component proteins was conducted to confirm that WD-Aptamer specifically binds to Dvl1_PDZ domain (Figure 2b). To establish the direct interaction between WD-Aptamer and Dvl1_PDZ domain by a fluorescence assay $\left(K_{\mathrm{d}}=284.8 \mathrm{nM}\right)$, fluorescence signals acquired by titration between WD-Aptamer and Dvl1_PDZ domain are shown in Figure 2c.

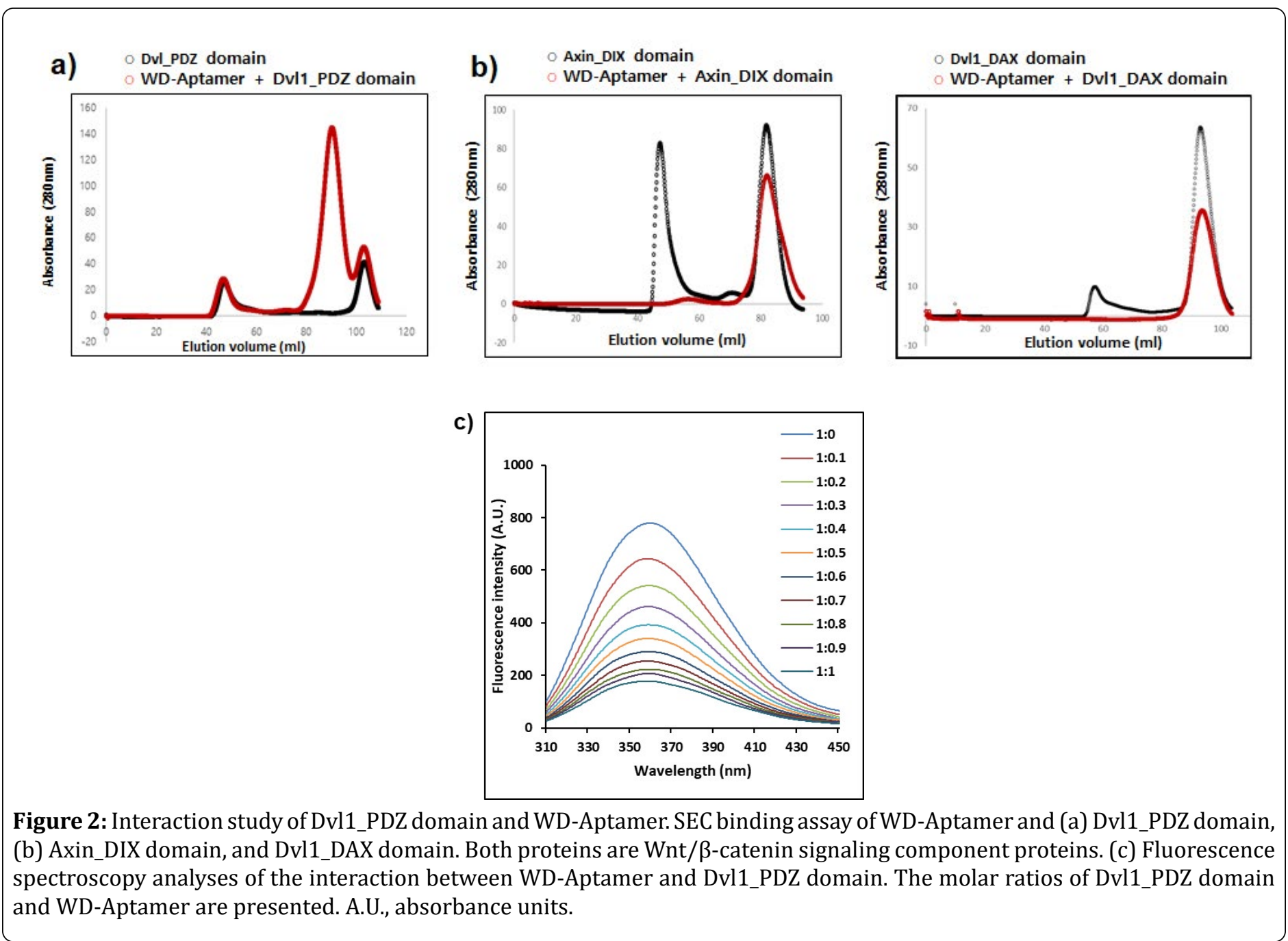

\section{Cell Penetration and Proliferation}

To demonstrate the ability of WD-Aptamer to enter HaCaT cells, Alexa Fluor ${ }^{\circledR}$ 555-labeled streptavidin was coupled with negative control or WD-Aptamer-biotin under identical conditions to measure fluorescence imaging. The fluorescence signal shows that a large portion of WDAptamer was entered into HaCaT cells compared to the negative control (Figure 3a). To examine the cell viability of WD-Aptamer itself, human keratinocyte cells (HaCaT) that spontaneously immortalized human epithelial cell lines were used. This experiment demonstrated that treatment with various concentrations of WD-Aptamer for $24 \mathrm{~h}$ significantly increased cell proliferation of human skin keratinocytes in a dose-dependent manner (Figure 3b). 
a)

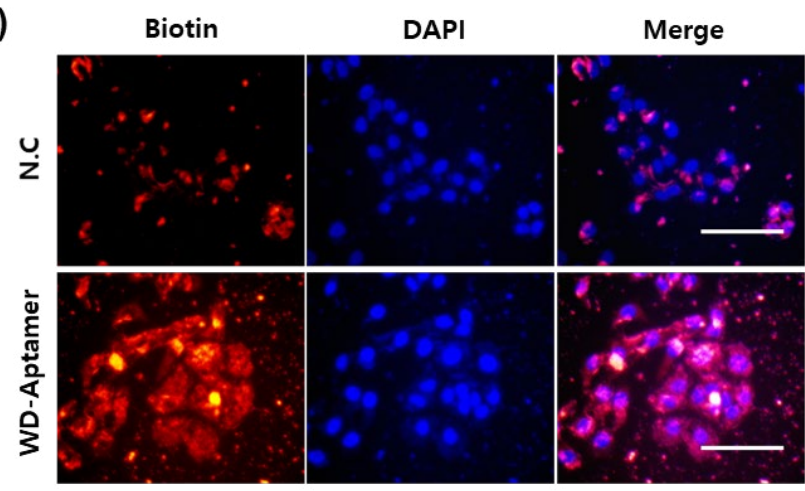

b)

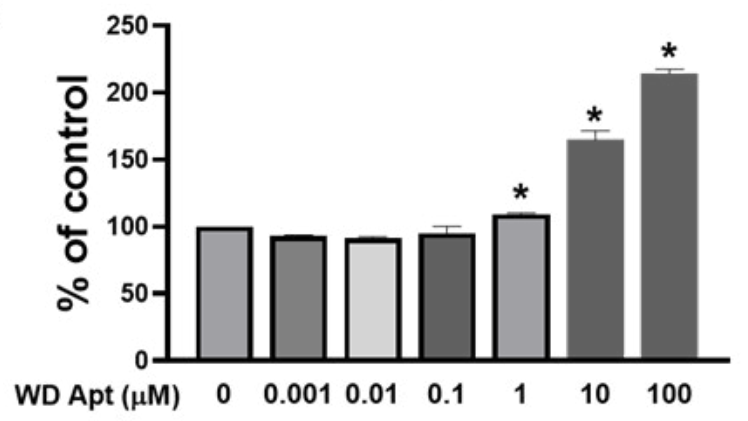

Figure 3: Cell penetration and proliferation. (a) Biotin-labeled aptamer (red) and nuclei marker DAPI (blue) were incubated with culture cells followed by fixation and imaging by a fluorescence microscope. Scale bar, $100 \mu \mathrm{m}$. (b) Cell viability in human keratinocyte cells (HaCaT) was determined using an MTT assay after treatment with WD-Aptamer for $24 \mathrm{~h}$.

\section{Conclusion}

Wnt/ $\beta$-catenin signaling plays a crucial role in bone formation, hair regrowth, and wound healing. CXXC5 is a negative regulator of the Wnt/ $\beta$-catenin signaling pathway. WD-Aptamer binds to Dvl1_PDZ domain and maintains the Wnt/ $\beta$-catenin signaling pathway. To the best of the authors' knowledge, WD-Aptamer has the potential for use in therapeutics in various fields.

\section{References}

1. Logan Catriona Y, Roel Nusse (2004) The Wnt signaling pathway in development and disease. Annu Rev Cell Dev Bio 20: 781-810.

2. MacDonald, Bryan T., Keiko Tamai, Xi He (2009) Wnt/ $\beta$-catenin signaling: components, mechanisms, and diseases. Developmental cell 17(1): 9-26.

3. He TC, Sparks AB, Rago C, Hermeking H, Zawel L, et al. (1998) Identification of c-MYC as a target of the APC pathway. Science 281(5382): 1509-1512.
4. Shtutman M, Zhurinsky J, Simcha I, Albanese C, D’Amico $M$ et al. (1999)The cyclin D1 gene is a target of the $\beta$-catenin/LEF-1 pathway. Proceedings of the National Academy of Sciences 96(10): 5522-5527.

5. Osamu T, McCormick $F$ (1999) $\beta$-Catenin regulates expression of cyclin D1 in colon carcinoma cells. Nature 398(6726): 422-426.

6. Crawford HC, Fingleton M, Rudolph-Owen LA, Goss KJ, Rubinfeld B, et al. (1999) The metalloproteinase matrilysin is a target of $\beta$-catenin transactivation in intestinal tumors. Oncogene 18(18): 2883-2891.

7. Koh Theodore J, Clemens J Bulitta, John V Fleming, Graham J Dockray, Andrea Varro, et al. (2000) Gastrin is a target of the $\beta$-catenin/TCF- 4 growth-signaling pathway in a model of intestinal polyposis. The Journal of clinical investigation 106(4): 533-539.

8. Kolligs Frank T, Marvin T Nieman, Ira Winer, Gang Hu, David Van Mater, et al. (2002) ITF-2, a downstream target of the Wnt/TCF pathway, is activated in human 


\section{Clinical Dermatology Open Access Journal}

cancers with $\beta$-catenin defects and promotes neoplastic transformation. Cancer cell 1(2): 145-155.

9. Andersson T, Södersten E, Duckworth JK, Cascante A, Fritz N, et al. (2009) CXXC5 is a novel BMP4-regulated modulator of Wnt signaling in neural stem cells. Journal of Biological Chemistry 284(6): 3672-3681.

10. Kim HY, Yoon JY, Yun JH, Cho KW, Lee SH, et al. (2015) CXXC5 is a negative-feedback regulator of the Wnt/ $\beta$ catenin pathway involved in osteoblast differentiation. Cell Death \& Differentiation 22(6): 912-920.

11. Lee Soung-Hoon, Mi-Yeon Kim, Hyun-Yi Kim, Young-Mi Lee, Heesu Kim, et al. (2015) The Dishevelled-binding protein CXXC5 negatively regulates cutaneous wound healing. Journal of Experimental Medicine 212(7): 10611080.

12. Lee, Soung-Hoon, Seol Hwa Seo, Dong-Hwan Lee, LongQuan Pi, Won-Soo Lee, et al. (2017) Targeting of CXXC5 by a competing peptide stimulates hair regrowth and wound-induced hair neogenesis. Journal of Investigative Dermatology 137(11): 2260-2269.

13. Proske D, Blank M, Buhmann R, Resch A (2005) Aptamers-basic research, drug development, and clinical applications. Applied microbiology and biotechnology 69(4): 367-374.

14. Tuerk C, Larry G (1990) Systematic evolution of ligands by exponential enrichment: RNA ligands to bacteriophage T4 DNA polymerase. Science 249(4968): 505-510.

15. Ellington AD, Szostak JW (1990) In vitro selection of RNA molecules that bind specific ligands. Nature 346(6287): 818-822.
16. Nimjee SM, White RR, Becker RC, Sullenger BA (2010) Aptamers as therapeutics. Nature reviews Drug discovery 9(7): 537-550.

17. Wang P, Yang Y, Hong H, Zhang Y, Cai W, Fang D, et al. (2011) Aptamers as therapeutics in cardiovascular diseases. Curr Med Chem 18(27): 4169-4174.

18. Liss M, Petersen B, Wolf H, Prohaska E (2002) An aptamer-based quartz crystal protein biosensor. Analytical Chemistry 74(17): 4488-4495.

19. Esposito CL, Catuogno S, de Franciscis V, Cerchia L. (2011) New insight into clinical development of nucleic acid aptamers. Discovery medicine 11(61): 487-496.

20. Keefe AD, Cload ST (2008) SELEX with modified nucleotides. Current opinion in chemical biology 12(4): 448-456.

21. Eyetech Study Group (2002) Preclinical and phase 1A clinical evaluation of an anti-VEGF pegylated aptamer (EYE001) for the treatment of exudative age-related macular degeneration. Retina 22(2): 143-152.

22. Eyetech Study Group (2003) Anti-vascular endothelial growth factor therapy for subfoveal choroidal neovascularization secondary to age-related macular degeneration: phase II study results. Ophthalmology 110(5): 979-986.

23. Lee, Inhwan, Sooho Choi, Ji-Hye Yun, Seol hwa Seo, Sehee Choi, et al. (2017) Crystal structure of the PDZ domain of mouse Dishevelled 1 and its interaction with CXXC5. Biochemical and biophysical research communications 485(3): 584-590. 